09.1

\title{
Фоточувствительность оптических сенсоров на основе дихалькогенидов переходных металлов: влияние толщины на их спектральные характеристики
}

\author{
() А.Ю. Авдижиян, С.Д. Лавров, А.В. Кудрявцев, А.П. Шестакова, М.В. Васина \\ МИРЭА - Российский технологический университет, Москва, Россия \\ E-mail: artur-333@yandex.ru
}

Поступило в Редакцию 7 марта 2019 г.

В окончательной редакции 20 марта 2019 г.

Принято к публикации 20 марта 2019 г.

\begin{abstract}
Изготовлены образцы полевых транзисторов на основе твердых растворов дихалькогенидов переходных металлов. Методом фототоковой спектроскопии исследованы их спектральные характеристики. Представлены результаты теоретической оценки общего оптического поглощения двумерных полупроводников при различных толщинах образца и для разных длин волн оптического излучения с учетом многолучевой интерференции. Показано, что интерференционные эффекты вносят значительный вклад в изменение формы спектральных характеристик оптических сенсоров при изменении толщины фоточувствительного слоя дихалькогенидов переходных металлов.
\end{abstract}

Ключевые слова: двумерные полупроводники, спектроскопия, дихалькогениды переходных металлов, линейная оптика.

DOI: 10.21883/PJTF.2019.12.47918.17773

В настоящее время дихалькогениды переходных металлов (ДПМ) являются наиболее перспективным классом двумерных материалов для создания новых устройств опто- и наноэлектроники. Монослои ДПМ имеют прямую запрещенную зону шириной $1.2-2 \mathrm{eV}[1]$. На основе данных материалов уже создан ряд устройств опто- и наноэлектроники, например полевые транзисторы с отношением логических уровней $I_{\text {on }} / I_{\text {off }} \sim 10^{6}$ [2], источники света [3], высокочувствительные фотодетекторы [4] и газовые сенсоры на базе монослоев $\mathrm{MoS}_{2}$ [5] и т.д.

Для разработки устройств, основанных на ДПМ, необходимо четкое понимание их оптических и электрофизических свойств. На данный момент существует ряд работ, посвященных характеризации оптических параметров данного класса материалов. Стандартными оптическими методиками исследования такого класса материалов являются фотолюминесцентная спектроскопия и микроскопия [6], нелинейная спектроскопия второй гармоники [7] и т. д.

В настоящей работе для оценки влияния толщины ДПМ на оптические свойства устройств на их основе применялась методика фототоковой спектроскопии. Для этого были созданы образцы полевых транзисторов на основе ДПМ разной толщины. Для исследования были выбраны образцы четырехфазных твердых растворов ДПМ $\left(\mathrm{Mo}_{0.34} \mathrm{~W}_{0.66} \mathrm{SeS}\right)$, объемные кристаллы которых были выращены с помощью методики химического осаждения из газовой фазы. Выбор материалов обусловлен возможностью изменения характерных пиков поглощения путем изменения химического состава вещества [8].

Двумерные образцы были нанесены на подложки $\mathrm{Si} / \mathrm{SiO}_{2}$ методом механической эксфолиации из объемных слоистых кристаллов. На кристаллиты были нанесены электроды при помощи электронно-лучевой литографии (рис. 1,a). Таким же образом производилось напыление на нижнюю поверхность подложки для создания затвора. Оптические и электрические свойства полученных образцов анализировались с помощью стандартной методики фототоковой спектроскопии. Эта техника заключается в измерении тока, генерируемого фототранзистором при облучении светом с изменяющейся длиной волны и приложенном постоянном напряжении между истоком-стоком и затвором-истоком. Далее строится зависимость силы тока от длины волны падающего излучения. Для этого был создан многофункциональный экспериментальный стенд, представленный на рис. $1, b$.

В ходе проведенных экспериментальных исследований были получены зависимости фототока от длины волны для ряда образцов различной толщины (рис. 2). Видно, что с ростом толщины образцов растет и абсолютное значение фототока. Это объясняется общим увеличением числа фотогенерируемых носителей заряда в объеме функционального слоя ДПМ за счет увеличения объема полупроводника и уменьшения запрещенной зоны [9]. Заметно, что длина волны максимального фототока увеличивается с ростом числа атомных слоев ДПМ. В общем виде фототок может быть описан следующей формулой:

$$
I_{p c}=V_{d s} \frac{\partial G}{\partial n} \Delta n=\left[V_{d s} \frac{\partial G}{\partial n} \frac{D \tau}{e}\right] e \frac{P}{\hbar \omega} \alpha(\hbar \omega),
$$

где $P$ - мощность излучения, $G$ - электропроводность, $D$ - вероятность фотопреобразования (вероятность генерации несвязанного носителя заряда при поглощении фотона), $n$ - количество носителей заряда, $\tau$ - 


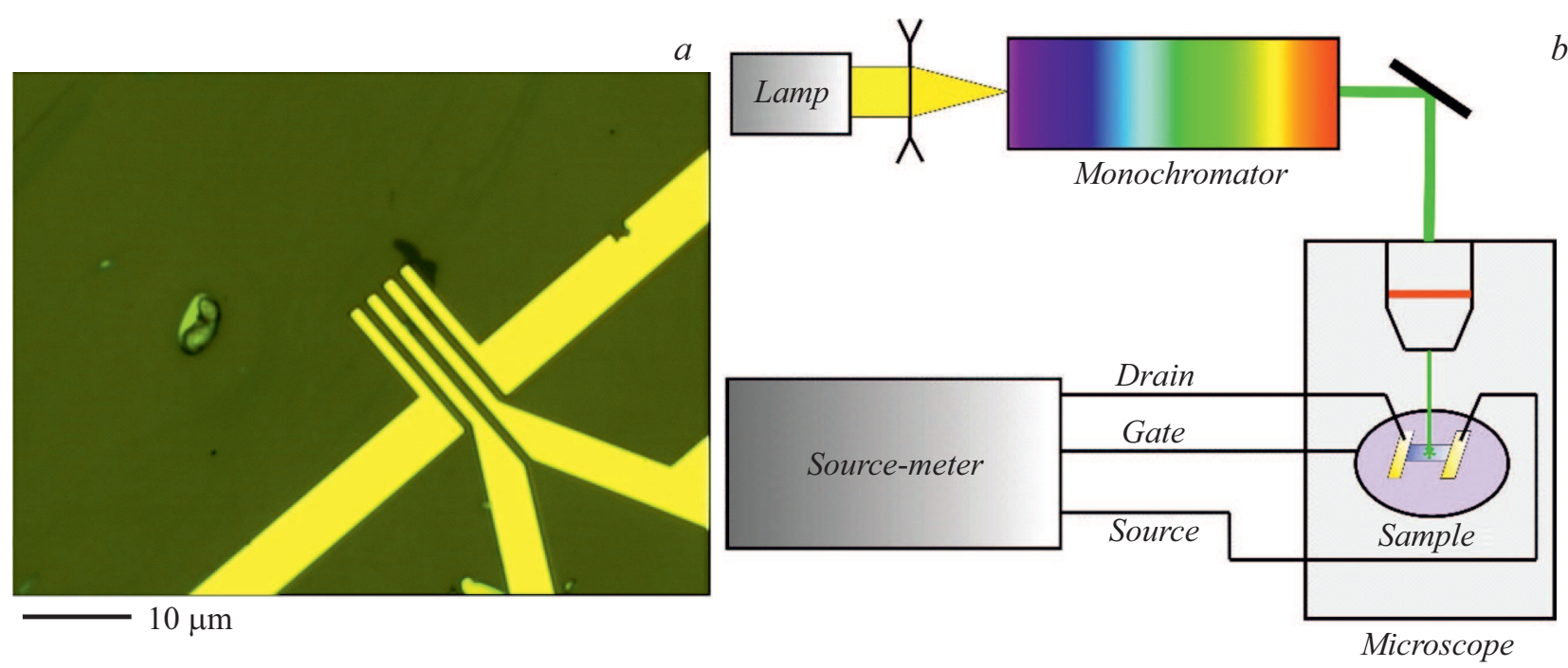

Рис. 1. Оптическое изображение созданного фототранзистора $(a)$ и общая схема экспериментальной установки $(b)$.

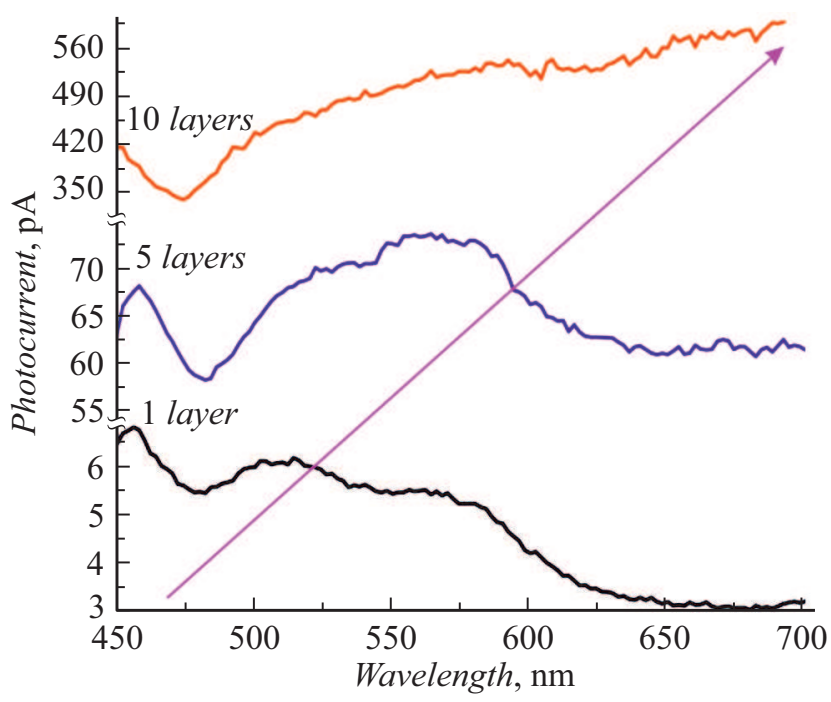

Рис. 2. Фоточувствительность при различных толщинах ДПМ.

время жизни фотоносителя, $e-$ заряд электрона, $\alpha-$ коэффициент поглощения [10].

Следует отметить, что выражение в квадратных скобках относится к фотогенерации (отношение количества носителей заряда к количеству поглощенных фотонов за единицу времени). Известно, что при изменении толщины ДПМ оптические коэффициенты отражения и поглощения могут меняться [11-13]. В указанных работах из-за технических сложностей прямого измерения оптических показателей кристаллитов, полученных с помощью методики механической эксфолиации, изучались пленки ДПМ, выращенные посредством химического осаждения. Однако материалы, полученные при помощи данных методик, могут значительно различаться по своим оптическим характеристикам [14]. В работе [11] представлена зависимость изменения показателя поглощения от толщины $\mathrm{MoS}_{2}$, однако корреляция этих параметров не является очевидной, и единственно возможный вывод состоит в том, что при увеличении толщины ДПМ поглощение смещается в ультрафиолетовую область. Тем не менее это идет вразрез с полученными экспериментальными результатами, из чего можно заключить, что данный механизм не играет определяющую роль в генерации фототока.

Для объяснения полученных экспериментальных зависимостей была использована теоретическая модель на основе уравнений Френеля. Данная модель успешно применяется для определения контрастности кристаллитов ДПМ, оценки эффективности люминесценции [15] и генерации второй гармоники [16]. Модель была модернизирована для оценки поглощения оптического излучения в слое ДПМ с учетом многолучевой интерференции. На рис. 3 представлены результаты проведенного моделирования. На их основе можно сделать вывод, что при изменении толщины слоя ДПМ от 1 до $15 \mathrm{~nm}$ максимум поглощения смещается в инфракрасную область (от 450 до $750 \mathrm{~nm}$ ), что коррелирует с полученными экспериментальными зависимостями.

Существенное изменение общего поглощения рассматриваемой структуры может быть объяснено наличием интерференционных механизмов. Данные механизмы являются хорошо изученными и используются при создании ряда оптических устройств, например интерференционных фильтров. Для двумерных слоев вклад линейных интерференционных эффектов рассматривался только при определении оптической контрастности в работе [17], где была показана сильная корреляция толщин слоев рассматриваемых структур и распределения в них оптических полей.

Таким образом, в работе показано, что на изменение зависимости фототока от длины волны в двумерных полупроводниках при увеличении толщины преимущественно оказывают влияние интерференционные эффек- 


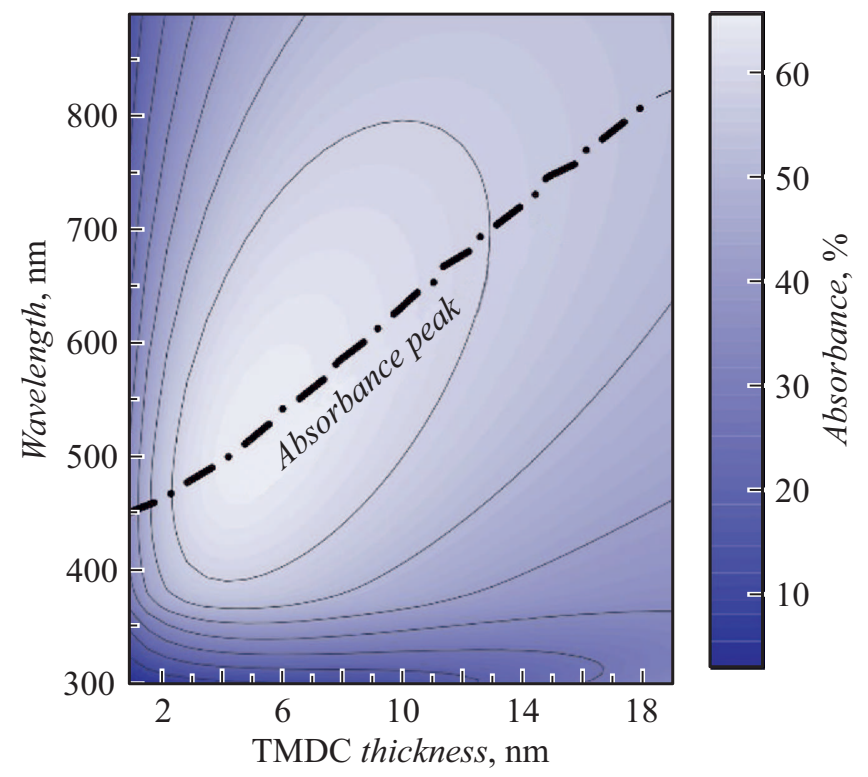

Рис. 3. 2D-карта смещения максимумов сдвига спектра.

ты. Также была разработана математическая модель для оценки вклада этих эффектов в изменение общего поглощения для образцов ДПМ разной толщины для различных длин волн. Теоретические результаты, полученные в приведенной модели, коррелируют с представленными экспериментальными данными.

\section{Финансирование работы}

Исследование выполнено при финансовой поддержке Российского фонда фундаментальных исследований в рамках научных проектов № 18-32-00831, 18-32-20047 и Министерства образования и науки РФ (государственное задание № 3.7335.2017/9.10) с использованием оборудования ЦКП РТУ-МИРЭА.

\section{Конфликт интересов}

Авторы заявляют, что у них нет конфликта интересов.

\section{Список литературы}

[1] Mann J., Ma Q., Odenthal P.M., Isarraraz M., Le D., Preciado E., Barroso D., Yamaguchi K., von Son Palacio G., Nguyen A., Tran T., Wurch M., Nguyen A., Klee V., Bobek S., Sun D., Heinz T.F., Rahman T.S., Kawakami R., Bartels L. // Adv. Mater. 2014. V. 26. N 9. P. 1399-1404.

[2] Yao J., Zheng Z., Yang G. // ACS Appl. Mater. Interfaces. 2016. V. 8. N 20. P. 12915-12924.

[3] Butun S., Tongay S., Aydin K. // Nano Lett. 2015. V. 15. N 4. P. 2700-2704.

[4] Лавров С.Д., Шестакова А.П., Мишина Е.Д., Ефименков Ю.Р., Сигов А.С. // ФТП. 2018. Т. 52. В. 6. С. 625-629.

[5] Huo N., Yang S., Wei Z., Li S.-S., Xia J.-B., Li J. // Sci. Rep. 2015. V. 4. N 1. P. 5209.
[6] Лавров С.Д., Шестакова А.П., Авдижиян А.Ю., Мишина Е.Д. // Письма в ЖТФ. 2018. Т. 44. В. 22. С. 19-24.

[7] Брехов К.А., Гришунин К.А., Ильин Н.А., Шестакова А.П., Лавров С.Д., Мишина Е.Д. // Письма в ЖТФ. 2017. Т. 43. B. 24. C. $46-52$.

[8] Huang J., Wang W., Fu Q., Yang L., Zhang K., Zhang J., Xiang B. // Nanotechnology. 2016. V. 27. N 13. P. 13LT01.

[9] Roldán R., Castellanos-Gomez A., Cappelluti E., Guinea F. // J. Phys.: Condens. Matter. 2015. V. 27. N 31. P. 313201.

[10] Klots A.R., Newaz A.K.M., Wang B., Prasai D., Krzyzanowska H., Lin J., Caudel D., Ghimire N.J., Yan J., Ivanov B.L., Velizhanin K.A., Burger A., Mandrus D.G., Tolk N.H., Pantelides S.T., Bolotin K.I. // Sci. Rep. 2015. V. 4. N 1. P. 6608

[11] Yim C., O'Brien M., McEvoy N., Winters S., Mirza I., Lunney J.G., Duesberg G.S. // Appl. Phys. Lett. 2014. V. 104. N 10. P. 103114.

[12] Cui Q., Ceballos F., Kumar N., Zhao H. // ACS Nano. 2014. V. 8. N 3. P. 2970-2976.

[13] Molina-Sánchez A., Hummer K., Wirtz L. // Surf. Sci. Rep. 2015. V. 70. N 4. P. 554-586.

[14] Plechinger G., Mann J., Preciado E., Barroso D., Nguyen A., Eroms J., Schüller C., Bartels L., Korn T. // Semicond. Sci. Technol. 2014. V. 29. N 6. P. 064008.

[15] Amani M., Burke R.A., Ji X., Zhao P., Lien D.-H., Taheri P., Ahn G.H., Kirya D., Ager J.W., Yablonovitch E., Kong J., Dubey M., Javey A. // ACS Nano. 2016. V. 10. N 7. P. 6535-6541.

[16] Лавров С.Д. // Рос. технол. журн. 2016. Т. 4. № 4. С. 3-12.

[17] Blake P., Hill E.W., Castro Neto A.H., Novoselov K.S., Jiang D., Yang R., Booth T.J., Geim A.K. // Appl. Phys. Lett. 2007. V. 91. N 6. P. 063124. 